\title{
Do age and sex influence on functional movement in school-age children? ¿Influyen la edad y el sexo en la funcionalidad del movimiento de niños en edad escolar? *Felipe Garcia-Pinillos, **Juan Párraga-Montilla, ***Luis E Roche-Seruendo, *Pedro Delgado-Floody, *Cristian PMartínez- Salazar, **Pedro ALatorre-Román \\ *Universidad de La Frontera (Chile), **Universidad de Jaén (España), ***Universidad San Jorge (España)
}

\begin{abstract}
The aim of this study was to determine the influence of age and sex on the functional movement in Spanish primary school children. A group of 172, 6-11 years old children (83 girls and 89 boys), participated in this study. The main outcome measures were the Functional Movement Screen ${ }^{\mathrm{TM}}$ (FMS), sex and chronological age of children. The ANCOVA (BMI as a covariate) revealed significant differences between age groups (p=0.003) but no between-sex differences (pe»0.05) in FMS total score. As for individual FMS tests, significant differences between age groups ( $<<0.05$ ) were found in the in-line lunge and the shoulder mobility tests; whereas, according to sex, significant differences $(\mathrm{p}<0.05)$ were found in the in-line lunge test (under 10 years old group) and the push-up test (under 12 group). The stepwise linear regression analysis revealed BMI as a primary predictor of FMS total score in school age children, but with a significant additional contribution from age $\left(R^{2}=0.206, p<0.001\right)$, whereas the sex was excluded from this model $(\mathrm{p}=0.097)$. In conclusion, the results reported in this study suggest that age is a moderate determinant of FMS scores, whereas sex is not a determinant in this battery test in school age children (6-11 years old). This study also highlights that BMI is the primary predictor of FMS total score in school age children, but with a significant additional contribution from age, whereas the sex was excluded from this model.
\end{abstract}

Key words: assessment; children; functional movement screen; gender; maturation.

Resumen. El objetivo de este estudio fue determinar la influencia de la edad y el sexo en la funcionalidad del movimiento de niños españoles en edad escolar. Un grupo de 172, 6-11 años (83 niñas y 89 niños), participaron en este estudio. Las variables medidas en el estudio fueron el rendimiento en el Functional Movement Screen ${ }^{\mathrm{TM}}$ (FMS), el sexo y la edad cronológica de los niños. Un ANCOVA (BMI como covariable) reveló diferencias significativas en la puntuación total obtenida en el FMS entre grupos de edad ( $\mathrm{p}=0.003$ ) pero no entre sexos (pe»0.05). En cuanto a los tests individuales incluidos en la batería, se hallaron diferencias entre grupos de edad en el test de lunge en línea y movilidad de hombro; mientras en relación al sexo, se hallaron diferencias significativas ( $\mathrm{p}<0.05$ ) se encontraron en el lunge en línea (en el grupo sub-10 años) y en el test de push-up (sub-12). El análisis de regresión lineal señaló al BMI como el principal predictor del rendimiento en FMS en escolares, con una significativa contribución de la variable edad $\left(R^{2}=0.206\right.$, $\left.p<0.001\right)$, y la variable sexo excluida del modelo ( $\left.\mathrm{p}=0.097\right)$. En conclusión, los resultados reportados en este estudio sugieren que la edad es un predictor moderado del rendimiento total en FMS en niños en edad escolar, el sexo no parece determinar el rendimiento, mientras que el BMI resulta predictor primario de la puntuación total en el FMS en escolares españoles (6-11 años).

Palabras clave: evaluación; niños; evaluación de funcionalidad de movimiento; género; maduración.

\section{Introduction}

Although numerous methods for assessing movement proficiency exist, a test battery that has become very popular is the Functional Movement Screen ${ }^{\mathrm{TM}}$ (FMS) (Chorba, Chorba, Bouillon, Overmyer, \& Landis, 2010; Cook, Burton, \& Hoogenboom, 2006; Lloyd et al., 2015). The movement patterns examined in the FMS place the athlete in positions where functional movement limitations and asymmetries may be identified (Bardenett et al., 2015). The FMS was originally designed to assess muscle flexibility, strength imbalances and general movement proficiency in a range of performancetests; identify functional deficits related to proprioception, mobilisation and stabilisation; and determine the existence of pain during any of the prescribed movement patterns (Cook et al., 2006).

The FMS consists of seven tests, each scored between zero and three points with three representing the best possible score. The composite score, or total screen score, ranges from 0 to 21 points. The seven tests include the deep squat, hurdle step, in-line lunge, shoulder mobility, active straight-leg raise (SLR), trunk stability push-up, and rotary stability tests. Descriptions of the tests and scoring criteria have been previously described(Abraham, Sannasi, \& Nair, 2015; Bardenett et al., 2015; Cook et al., 2006).

Many papers have been published in recent years about FMS and its usefulness and validity in different populations and with different purposes (García-Jaén, Sellés-Pérez, Cortell-Tormo, Férriz-Valero, \& Cejuela, 2018; Gonzalo-Skok, Serna, Rhea, \& Marín, 2015; Perry \& Koehle, 2013; Schneiders, Davidsson, Hörman, \& Sullivan, 2011), although the results are controversial. While some lately published papers question the value of FMS to predict injuries (Alemanya et al., 2017; Newton et al., 2017) and the apparent lack of relationships with performance tests in youth (Gonzalo-Skok et al., 2015), many works

Fecha recepción: 10-02-18. Fecha de aceptación: 05-06-18 Felipe Garcia Pinillos fegarpi@gmail.com keep using the FMS battery test as a measure of functional movement and movement proficiency in school-age children (Lloyd et al., 2015; O' Brien, Belton, \& Issartel, 2016). It seems clear that more research is needed to highlight the usefulness of this battery and its application to different populations. Specifically, the feasibility of this battery test in the school setting remains questioned. Of note, previous literature has noted the importance of effective movement proficiency for safe and effective long-term physical performance in young athletes (Cliff et al., 2012; Lloyd \& Oliver, 2012; Lubans, Morgan, Cliff, Barnett, \& Okely, 2010; O' Brien et al., 2016) and the FMS test is an evidence-based way to assess functional movement (as well as no equipment is strictly needed) (Cook et al., 2006) so that, its use in the school setting may be justified.

At these ages characterized by severe anthropometric changes, motor skills and movement proficiency seem to be influenced by maturation (Lloyd et al., 2015) and sex (García-Jaén et al., 2018). However, limited evidence is available about the effect of such an important variables at prepubertal ages. The study of Lloyd et al. (Lloyd et al., 2015) involved thirty 11-16 years old males, whereas the work recently published by García-Jaén et al. (García-Jaén et al., 2018), involved forty 8-9 years old (twenty males and twenty females). The reduced sample size limits the impact of those findings and makes difficult to determine the effect of age and sex in the same study. Additionally, previous studies have identified that fundamental movement skills are negatively influenced by overweight or obesity (Cliff et al., 2012; Morano, Colella, \& Caroli, 2011). More specifically, previous works have reported that poorer functional movement was associated with higher body mass index (BMI) and lower levels of physical activity in British children (Duncan \& Stanley, 2012; Duncan et al., 2013).

In spite of growing interest in the use of FMS (or similar screening protocols) within athletic development programmes or school settings, limited evidence is available about the effect of such an important variables at prepubertal ages as age and sex. Therefore, the aim of this study is to determine the influence of age and sex on the functional movement in Spanish primary school children. 


\section{Methods}

\section{Participants}

A group of 172 children, 89 boys and 83 girls (age range $=6-11$ years; age $=9.70 \pm 1.55$ years; body mass $=37.36 \pm 13.61 \mathrm{~kg}$; height $=$ $1.39 \pm 0.13 \mathrm{~m} ; \mathrm{BMI}=18.90 \pm 4.45 \mathrm{~kg} / \mathrm{m}^{2}$ ) participated in this study. They were selected from different schools in southern Spain. The sample has been selected by convenience in a large geographic area of Andalusia in both urban and rural areas. Inclusion criteria included being free from physical and/or intellectual disabilities. Exclusion criteria included: (i) the use of a mobility aid or prophylactic device (e.g., knee brace); (ii) a musculoskeletal impairment or injury or head injury $(<6$ weeks) which was likely to affect their motor performance; (iii) to be diagnosed with any form of developmental disorder likely to influence motor performance were also not included (i.e., developmental coordination disorder, dyspraxia, dyslexia, Asperger's syndrome and autism). Parents voluntarily signed an informed consent form for the participation of their children in this study. The study was completed in accordance with the norms of the Declaration of Helsinki (2013 version) (World Medical Association, 2013) and following the directives of the European Union on Good Clinical Practice (111/3976/88 of July, 1990), as specified in the Spanish legal framework for human clinical research (Royal Decree 561/1993 on clinical essays). The study was approved by the Ethics Committee of the University of Jaen (Jaen, Spain).

\section{Procedures}

\section{Anthropometry}

Body height $(\mathrm{cm})$ was measured with a stadiometer (Seca 222, Hamburg, Germany, precision=1 mm) and body mass with a weighing scale (Seca 899, Hamburg, Germany, precision=100g). Children were assessed in bare feet and lightly clothed (sport clothes) and measurements were taken by anthropometrists accredited by using the standard International Association for the Advancement of Kinanthropometry (ISAK) protocol for such measurements. From this, body mass index was determined as $\mathrm{kg} / \mathrm{m}^{2}$.

\section{Functional movement assessment}

The Functional Movement Screen ${ }^{\mathrm{TM}}\left(\mathrm{FMS}^{\mathrm{TM}}\right)$ is a pre-participation screening tool which evaluates the Fundamental Movement Patterns that underpin performance of all movement (Cook et al., 2006). The FMS consists of seven tests: deep squat, in-line lunge, hurdle step, shoulder mobility, stability push-up, rotational stability and active SLR, which challenge an individual's ability to perform basic movement patterns that reflect combinations of muscle strength, flexibility, range of motion, coordination, balance and proprioception (Cook et al., 2006). The FMS was administered by a trained rater using standardised procedures, instructions and scoring processes (Cook et al., 2006). Each participant was given 3 trials on each of the seven tests in accordance with recommended guidelines (Cook et al., 2006). Each trial was scored from 0 to 3 with higher scores reflecting better functional movement. In regard to the criteria for scoring on the FMS, a score of ' 3 ' is awarded for perfect execution of the movement, ' 2 ' for execution that demonstrates compensation and less than perfect form, ' 1 ' where there is inability to complete the movement pattern because of stiffness, loss of balance or another difficulty and a score of ' 0 ' is awarded if there is pain when performing the movement. Comprehensive instructions for each movement are also provided elsewhere (Cook et al., 2006).

For each test, the highest score from the three trials was recorded and used for analysis. These scores were also summed to generate an overall composite FMS score with a maximum value of 21 and in accordance with recommended protocols (Cook et al., 2006; Schneiders et al., 2011). In the present study both the composite FMS score and individual scores for each component of the FMS were used. This is consistent with previous research with children (Duncan et al., 2013). The composite FMS score provides a holistic evaluation of an individual's functional movement (Cook et al., 2006). However, individual scores for each of the FMS tests are needed to determine an individual's consistency of movement, to determine whether there is a specific movement dysfunction (Cook et al., 2006).

Although independent research examining the validity and reliability of the individual tests within the FMS is not available in children, some studies have previously used it in that population (Duncan et al., 2013; Gonzalo-Skok et al., 2015; Lloyd et al., 2015; Schneiders et al., 2011). Additionally, a previous work (Schneiders et al., 2011) with young people (18-40 y) determined an excellent inter-rater reliability (ICC) for the composite FMS score, and for individual test components of the FMS (Kappa). Likewise, in a study with school-age children (Duncan et al., 2013) kappa values revealed excellent test re-test agreement for total composite score and individual FMS tests (Kappa $=0.97$ to 1 ).

\section{Statistical analysis}

Data were analysed using SPSS, v.21.0 for Windows (SPSS Inc, Chicago, USA) and the significance level was set at $\mathrm{p}<0.05$. Test of normal distribution (Kolmogorov-Smirnov) were conducted on all data before analysis. Regarding the age effect, three groups were created (under 8 [U-8]: 6-7 years old; under 10 [U-10]: 8-9; under 12 [U-12]: 10-11) and repeated measures analysis of covariance (ANCOVA), using BMI as a covariate, was conducted for FMS total score. Where any significant differences were found post-hoc analysis employing the Bonferroni test was used to determine where these differences lay. To determine the sex influence, an ANCOVA, using BMI as a covariate, was conducted in every age group for FMS total score. As for the individual tests, a non-parametric analysis was performed. The KruskalWallis test was conducted between age groups for each individual test, with U Mann-Whitney as a post-hoc test. To determine the influence of sex on each individual FMS test, the U Mann-Whitney test was conducted for each test at each age group. Additionally, a partial correlation analysis was performed between age, BMI and FMS total score, adjusting by sex. Finally, BMI, age, and sex were entered into multiple linear regression along with the FMS total score to determine the determinants of performance at school age.
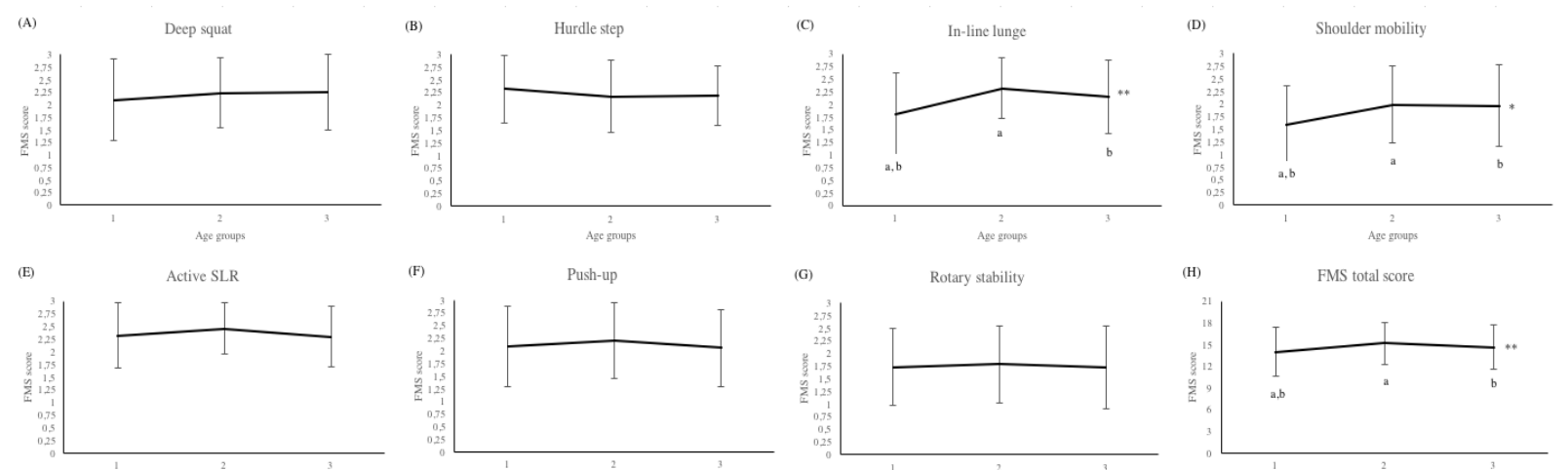

Figure 1. Age effect on FMS battery test score, total and individual tests: (A) deep squat test, (B) hurdle step test, (C) in -line lunge test, (D) shoulder mobility test, (E) active SLR test, (F) push-up test, (G) rotary stability test, (H) FMS total score. FMS: Functional Movement Screen ${ }^{\mathrm{TM}}$ battery test; SLR: straight-leg raise; Age groups: 1 includes 6-7 years old, 2 includes 8-9 years old and 3 includes $10-11$ years old. ${ }^{*} \mathrm{p}<0.05, * * \mathrm{*}<0.01, * * * \mathrm{p}<0.001$; same superscript letter indicates significant differences between those age groups. 


\section{Results}

Figure 1 shows the effect of age on FMS score in school age children. The ANCOVA showed significant differences between age groups in the FMS total ( $\mathrm{p}=0.003$ ) with post-hoc differences between U-8 vs. U-10 and U-12 ( $p=0.014$ and 0.004 , respectively). The nonparametric analysis for individual FMS tests (Kruskal-Wallis test) reported no significant differences between age groups in the squat ( $\mathrm{p}=0.652$ ), hurdle step ( $\mathrm{p}=0.447$ ), active SLR ( $\mathrm{p}=0.232$ ), push-up $(p=0.644)$ nor rotary stability $(p=0.885)$ tests. Significant differences were found in the in-line lunge test $(\mathrm{p}=0.009)$ with post-hoc test showing differences between U-8 and U-10 ( $\mathrm{p}=0.001)$ and $\mathrm{U}-12(\mathrm{p}=0.002)$, and in the shoulder mobility test $(\mathrm{p}=0.031)$ with post-hoc revealing differences between U-8 and U-10 ( $p=0.009)$ and U-12 ( $\mathrm{p}=0.001)$.

Table 1 shows the sex comparison for FMS battery test (FMS total and individual tests). The ANCOVA showed no significant between-sex differences (pe»0.05) in FMS total score at any age group (U-8, U-10 or U-12). The non-parametric analysis for individual FMS tests (U Mann-Whitney test) reported no significant between-sex differences (pe»0.05) in the U-8 group in any of the individual tests; whereas, in the U-10 group, significant between-sex differences $(\mathrm{p}=0.012)$ were found in the in-line lunge test, and in the push-up test $(\mathrm{p}=0.034)$ in the $\mathrm{U}-12$ group.

\begin{tabular}{|c|c|c|c|c|c|c|c|c|c|}
\hline & & $\begin{array}{l}\text { Deep } \\
\text { squat }\end{array}$ & $\begin{array}{c}\text { Hurdle } \\
\text { step }\end{array}$ & $\begin{array}{l}\text { In-line } \\
\text { lunge }\end{array}$ & $\begin{array}{l}\text { Shoulder } \\
\text { Mobility } \\
\end{array}$ & $\begin{array}{c}\text { Active } \\
\text { SLR }\end{array}$ & Push-up & $\begin{array}{l}\text { Rotary } \\
\text { stability }\end{array}$ & $\begin{array}{l}\text { Total } \\
\text { score }\end{array}$ \\
\hline \multirow{2}{*}{$\begin{array}{l}\text { Under } 8 \\
(\mathrm{n}=37)\end{array}$} & $\begin{array}{c}\mathrm{M} \\
(\mathrm{n}=24)\end{array}$ & $\begin{array}{c}2.08 \\
(0.88)\end{array}$ & $\begin{array}{c}2.33 \\
(0.69)\end{array}$ & $1.79(0.88)$ & $1.50(0.78)$ & $\begin{array}{c}2.21 \\
(0.57)\end{array}$ & $\begin{array}{c}2.13 \\
(0.79)\end{array}$ & $\begin{array}{c}1.71 \\
(0.75)\end{array}$ & $\begin{array}{l}13.75 \\
(3.05)\end{array}$ \\
\hline & $\underset{(n=13)}{F}$ & $\begin{array}{c}2.15 \\
(0.69)\end{array}$ & $\begin{array}{c}2.31 \\
(0.62)\end{array}$ & $1.85(0.79)$ & $1.77(0.74)$ & $\begin{array}{c}2.54 \\
(0.88)\end{array}$ & $\begin{array}{c}2.00 \\
(0.82)\end{array}$ & $\begin{array}{c}1.77 \\
(0.83)\end{array}$ & $\begin{array}{l}14.39 \\
(3.95)\end{array}$ \\
\hline \multirow{2}{*}{$\begin{array}{l}\text { Under } 10 \\
(\mathrm{n}=54)\end{array}$} & $\begin{array}{c}\mathrm{M} \\
(\mathrm{n}=22)\end{array}$ & $\begin{array}{c}2.05 \\
(0.63)\end{array}$ & $\begin{array}{c}2.23 \\
(0.68)\end{array}$ & $2.05(0.75)$ & $1.86(0.77)$ & $\begin{array}{c}2.36 \\
(0.58)\end{array}$ & $\begin{array}{c}2.23 \\
(0.78)\end{array}$ & $\begin{array}{c}1.68 \\
(0.71)\end{array}$ & $\begin{array}{r}14.45 \\
(3.01)\end{array}$ \\
\hline & $\underset{(\mathrm{n}=32)}{\mathrm{F}}$ & $\begin{array}{c}2.38 \\
(0.71)\end{array}$ & $\begin{array}{c}2.13 \\
(0.75)\end{array}$ & $\begin{array}{c}2.50 \\
(0.75)^{*}\end{array}$ & $2.06(0.76)$ & $\begin{array}{c}2.56 \\
(0.50)\end{array}$ & $\begin{array}{c}2.16 \\
(0.77)\end{array}$ & $\begin{array}{c}1.85 \\
(0.80)\end{array}$ & $\begin{array}{l}15.63 \\
(2.81)\end{array}$ \\
\hline \multirow{2}{*}{$\begin{array}{c}\text { Under } 12 \\
(\mathrm{n}=81)\end{array}$} & $\underset{(n=43)}{M}$ & $\begin{array}{c}2.28 \\
(0.67)\end{array}$ & $\begin{array}{c}2.12 \\
(0.50)\end{array}$ & $2.07(0.63)$ & $1.81(0.72)$ & $\begin{array}{c}2.23 \\
(0.61)\end{array}$ & $\begin{array}{c}2.23 \\
(0.72)\end{array}$ & $\begin{array}{c}1.74 \\
(0.84)\end{array}$ & $\begin{array}{l}14.49 \\
(3.05)\end{array}$ \\
\hline & $\begin{array}{c}\mathrm{F} \\
(\mathrm{n}=38)\end{array}$ & $\begin{array}{c}2.21 \\
(0.84)\end{array}$ & $\begin{array}{l}2.26 \\
(0.68)\end{array}$ & $2.24(0.71)$ & $2.13(0.72)$ & $\begin{array}{c}2.37 \\
(0.60)\end{array}$ & $\begin{array}{c}1.87 \\
(0.77)^{*}\end{array}$ & $\begin{array}{c}1.68 \\
(0.77)\end{array}$ & $\begin{array}{l}14.76 \\
(3.02)\end{array}$ \\
\hline
\end{tabular}

The partial correlation analysis reported a significant correlation between BMI and FMS total score $(r=-0.385, \mathrm{p}<0.001)$. Results of the linear regression analysis revealed BMI as a primary predictor of FMS total score in school age children, but with a significant additional contribution from age $\left(R^{2}=0.206, p<0.001\right)$. Sex was excluded from this model $(\mathrm{p}=0.097)$.

\section{Discussion}

This study aimed to determine the influence of age and sex on the functional movement in Spanish primary school children. The main finding of the current study is that BMI was identified as a primary predictor of FMS total score in school age children, but with a significant additional contribution from age, whereas the sex was excluded from this model. Additionally, from the isolated analysis of the age and sex effects, the data revealed that: (i) age is a determinant factor just in the inline lunge and the shoulder mobility tests (2 out of 7) along with total FMS score; (ii) whereas sex had not effect in the U-8 group, and a very small effect in the U-10 (just 1 out of 7 tests: in-line lunge test) and in the U-12 group (just 1 out of 7 tests: push up test).

However, some appreciations must be taken into consideration to correctly interpret these findings. First, the results obtained, indirectly, indicate that FMS total score may overlook important information. If we look to our data, FMS total and individual tests report in, some cases, contradictory information. This is in line with the approach by Lloyd et al. (Lloyd et al., 2015) that consider both total and individual scores in their analysis, and it is also in consonance with the findings reported by Alemanya et al. (Alemanya et al., 2017) who question the utility of total score and cut-off points in the FMS battery test.

Second, the results obtained provide support to the theory of nonlinear development of children (Malina, 2012) (6-11 years old in this case), with periods of relatively little fluctuation followed by periods of rapid change. In the current study, none of the performance variables (except the in-line lunge and shoulder mobility tests) were significantly different between age groups. This finding is consistent with that reported by Lloyd et al. (Lloyd et al., 2015) who found no improvement in reactive strength index, agility or FMS scores between 9-13 years old children with the authors suggesting that this may be associated with a general plateau in performance.

Focusing on the mean composite score, the value reported in this study is 14.59 which is exactly the same than that reported for adolescent school age children (10-17 years old), and lower than the score for active people between 18-40 years old (mean score 15.7) (Schneiders et al., 2011) and professional male football players (mean score 16.9) (Kiesel, Plisky, \& Voight, 2007). The normative value reported in middle aged adults is 14.14 (Perry \& Koehle, 2013), which was similar to the mean composite score reported for the children in this study. It might be expected that professional football players or active adults would score better due to their physical maturity, conditioning, fitness, age, and body composition, compared to the status of 6-11 years old children but no strong correlation of FMS composite scores with any of the variables studied. For example, focusing on the age effect, a target variable in this study, Abraham et al. (Abraham et al., 2015) found a weak negative correlation between FMS total score and age in adolescent ( $\mathrm{r}=$ -0.038), whereas age was significantly related to FMS scores in middle age adults (Perry \& Koehle, 2013).

As for the sex influence, Abraham et al. (Abraham et al., 2015) reported similar results to our study with between sex differences lower than 1 point in adolescent children. However, considering the individual tests scores, the aforementioned study (Abraham et al., 2015) found between sex differences on four individual FMS tests reporting that males were on average better on the in-line lunge, active SLR, pushup and the rotary stability tests than females. On average, our study found females better on the in-line lunge (8-9 years old) while males were better on push-up (10-11 years old) with no between sex differences in the younger children (6-7 years old group). The authors suggest that the age of participants (the onset of adolescence) might be the reason for these differences. It is well known biological maturation influences physical performance, largely owing to alterations in hormonal profiles, increases in lean body mass, myelination of motor neurons and enhanced inter- and intramuscular coordination (Faigenbaum, Lloyd, \& Myer, 2013; Lloyd et al., 2014). The rapid increases in body dimensions and limb lengths and significant development of muscle mass associated with maturation may affect, although with fluctuating levels, to movement proficiency during this stage of development(Quatman-Yates, Quatman, Meszaros, Paterno, \& Hewett, 2012).

Finally, some limitations need to be considered. First, the influence of potential confounding variables as level of physical activity, socioeconomic status and ethnic group. Second, biological maturation was not measured and the literature suggests that there exist significant interindividual differences as a result of maturational processes when children are grouped according to chronological age (Lloyd et al., 2015; Malina, 2012). Notwithstanding these limitations, the current study highlights the influence of age and sex on the FMS score of 6-12 years old children.

\section{Conclusion}

The results reported in this study suggest that age is a moderate determinant of FMS scores, whereas sex is not a determinant in this battery test in school age children (6-11 years old). This study also highlights that BMI is the primary predictor of FMS total score in school age children, but with a significant additional contribution from age, whereas the sex was excluded from this model. Additionally, these data indicate that FMS total score may overlook important information 
by providing opposing information to individual tests. Likewise, this study supports the theory of non-linear development of school-age children with periods of relatively little fluctuation followed by periods of rapid change.

From a practical standpoint, these data highlight the importance of implementing functional movement screening in the school setting in order to build up the traditionally performed physical fitness testing, and it warns physical education teachers and professional working with young athletes about the risks of comparing results with children of different ages, sexes and weight status.

\section{Acknowledgements}

The authors would like to thank to participants and schools and families that accepted to participate in this study.

\section{Authors' contributions}

FGP conceived the study and conducted the statistical analysis and drafted the manuscript; JAPM critically revised the manuscript; LERS critically revised the manuscript; PDF helped to draft the manuscript; CMS critically revised the manuscript; PALR helped to conceived the study and critically revised the manuscript.

\section{Competing interests}

None of the authors declare competing financial interests.

\section{Founding sources}

This research did not receive any specific grant from funding agencies in the public, commercial, or not-for-profit sectors.

\section{References}

Abraham, A., Sannasi, R., \& Nair, R. (2015). Normative values for the functional movement screen in adolescent school aged children. International Journal of Sports Physical Therapy, 10(1), 29-36. Retrieved from http://www.ncbi.nlm.nih.gov/pubmed/25709860

Alemanya, J. A., Bushman, T., Grier, T., Anderson, M. K., CanhamChervaka, M., North, W. J., \& Jones, B. H. (2017). Functional Movement Screen: Pain versus composite score and injury risk. Journal of Science and Medicine in Sport. https://doi.org/10.1016/ J.JSAMS.2017.08.001

Bardenett, S. M., Micca, J. J., DeNoyelles, J. T., Miller, S. D., Jenk, D. T., \& Brooks, G. S. (2015). Functional Movement Screen normative values and validity in high school athletes: can the FMSTM be used as a predictor of injury? International Journal of Sports Physical Therapy, 10(3), 303-8.

Chorba, R. S., Chorba, D. J., Bouillon, L. E., Overmyer, C. A., \& Landis, J. A. (2010). Use of a functional movement screening tool to determine injury risk in female collegiate athletes. North American Journal of Sports Physical Therapy/ : NAJSPT, 5(2), 47-54.

Cliff, D. P., Okely, A. D., Morgan, P. J., Jones, R. A., Steele, J. R., \& Baur, L. A. (2012). Proficiency Deficiency: Mastery of Fundamental Movement Skills and Skill Components in Overweight and Obese Children. Obesity, 20(5), 1024-1033. https://doi.org/10.1038/ oby.2011.241

Cook, G., Burton, L., \& Hoogenboom, B. (2006). Pre-participation screening: the use of fundamental movements as an assessment of function - part 1. North American Journal of Sports Physical Therapy/ : NAJSPT, 1(2), 132-9. Retrieved from http://www.ncbi.nlm.nih.gov/ pubmed/21522225

Duncan, M. J., \& Stanley, M. (2012). Functional movement is negatively associated with weight status and positively associated with physical activity in british primary school children. Journal of Obesity, 2012, 697563. https://doi.org/10.1155/2012/697563

Duncan, M. J., Stanley, M., \& Leddington Wright, S. (2013). The association between functional movement and overweight and obesity in British primary school children. BMC Sports Science, Medicine \& Rehabilitation, 5(1), 11. https://doi.org/10.1186/2052-1847-5-11

Faigenbaum, A. D., Lloyd, R. S., \& Myer, G. D. (2013). Youth Resistance Training: Past Practices, New Perspectives, and Future Directions. Pediatric Exercise Science, 25(4), 591-604. https://doi.org/10.1123/ pes.25.4.591
García-Jaén, M., Sellés-Pérez, S., Cortell-Tormo, J. M., Férriz-Valero, A., \& Cejuela, R. (2018). Assessment of fundamental movement patterns in children: a gender comparison on Primary School students. Retos/ : Nuevas Perspectivas de Educación Física, Deporte y Recreación., 34, 282-286. Retrieved from https://recyt.fecyt.es/index.php/retos/ article/view/65097

Gonzalo-Skok, O., Serna, J., Rhea, M. R., \& Marín, P. J. (2015). RELATIONSHIPS BETWEEN FUNCTIONAL MOVEMENT TESTS AND PERFORMANCE TESTS IN YOUNG ELITE MALE BASKETBALL PLAYERS. International Journal of Sports Physical Therapy, 10(5), 628-38.

Hills, A. P., Hennig, E. M., Byrne, N. M., \& Steele, J. R. (2002). The biomechanics of adiposity - structural and functional limitations of obesity and implications for movement. Obesity Reviews, 3(1), 3543. https://doi.org/10.1046/j.1467-789X.2002.00054.x

Kiesel, K., Plisky, P. J., \& Voight, M. L. (2007). Can Serious Injury in Professional Football be Predicted by a Preseason Functional Movement Screen? North American Journal of Sports Physical Therapy/ : NAJSPT, 2(3), 147-58. Retrieved from http:// www.ncbi.nlm.nih.gov/pubmed/21522210

Lloyd, R. S., Faigenbaum, A. D., Stone, M. H., Oliver, J. L., Jeffreys, I., Moody, J. a, ... Myer, G. D. (2014). Position statement on youth resistance training: the 2014 International Consensus. British Journal of Sports Medicine, 48(7), 498-505. https://doi.org/10.1136/bjsports2013-092952

Lloyd, R. S., \& Oliver, J. L. (2012). The Youth Physical Development Model. Strength and Conditioning Journal, 34(3), 61-72. https:// doi.org/10.1519/SSC.0b013e31825760ea

Lloyd, R. S., Oliver, J. L., Radnor, J. M., Rhodes, B. C., Faigenbaum, A. D., \& Myer, G. D. (2015). Relationships between functional movement screen scores, maturation and physical performance in young soccer players. Journal of Sports Sciences, 33(1), 11-19. https://doi.org/ 10.1080/02640414.2014.918642

Lubans, D. R., Morgan, P. J., Cliff, D. P., Barnett, L. M., \& Okely, A. D. (2010). Fundamental movement skills in children and adolescents: review of associated health benefits. Sports Medicine (Auckland, N.Z.), 40(12), 1019-35. https://doi.org/10.2165/11536850000000000-00000

Malina, R. M. (2012). Growth. In Encyclopedia of Exercise Medicine in Health and Disease (pp. 376-378). Springer Berlin Heidelberg. https:/ /doi.org/10.1007/978-3-540-29807-6_91

Morano, M., Colella, D., \& Caroli, M. (2011). Gross motor skill performance in a sample of overweight and non-overweight preschool children. International Journal of Pediatric Obesity, 6(S2), 42-46. https://doi.org/10.3109/17477166.2011.613665

Newton, F., McCall, A., Ryan, D., Blackburne, C., aus der Fünten, K., Meyer, T., ... McCunn, R. (2017). Functional Movement Screen $\left(\mathrm{FMS}^{\mathrm{TM}}\right)$ score does not predict injury in English Premier League youth academy football players. Science and Medicine in Football, 1(2), 102-106. https://doi.org/10.1080/24733938.2017.1283436

O’ Brien, W., Belton, S., \& Issartel, J. (2016). Fundamental movement skill proficiency amongst adolescent youth. Physical Education and Sport Pedagogy, 21(6), 557-571. https://doi.org/10.1080/ 17408989.2015.1017451

Perry, F. T., \& Koehle, M. S. (2013). Normative Data for the Functional Movement Screen in Middle-Aged Adults. Journal of Strength and Conditioning Research, 27(2), 458-462. https://doi.org/10.1519/ JSC.0b013e3182576fa6

Quatman-Yates, C. C., Quatman, C. E., Meszaros, A. J., Paterno, M. V, \& Hewett, T. E. (2012). A systematic review of sensorimotor function during adolescence: a developmental stage of increased motor awkwardness? British Journal of Sports Medicine, 46(9), 649-55. https://doi.org/10.1136/bjsm.2010.079616

Schneiders, A. G., Davidsson, A., Hörman, E., \& Sullivan, S. J. (2011). Functional movement screen normative values in a young, active population. International Journal of Sports Physical Therapy, 6(2), 75-82.

Williams, E. P., Mesidor, M., Winters, K., Dubbert, P. M., \& Wyatt, S. B. (2015). Overweight and Obesity: Prevalence, Consequences, and Causes of a Growing Public Health Problem. Current Obesity Reports, 4(3), 363-370. https://doi.org/10.1007/s13679-015-0169-4

World Medical Association. (2013). World Medical Association Declaration of Helsinki. JAMA, 310(20), 2191. https://doi.org/10.1001/ jama.2013.281053 